\title{
Application of Fourier-Transform Infrared Spectroscopy (FTIR) for the Study of Cultural Heritage Artifacts
}

\author{
Valentin Raditoiu $^{1}\left(\mathbb{D}\right.$, Irina Elena Chican ${ }^{1(\bowtie)}\left(\mathbb{D}\right.$, Alina Raditoiu ${ }^{1}$, \\ Irina Fierascu $^{1}$ (D), Radu Claudiu Fierascu ${ }^{1}$ (D), and Petronela Fotea ${ }^{2}$ \\ 1 The National Institute for Research and Development in Chemistry \\ and Petrochemistry - ICECHIM, 202 Spl. Independentei, \\ 060021 Bucharest, Romania \\ irina_chican@yahoo.com \\ ${ }^{2}$ Romanian Peasant Museum, 3 Kiseleff Str., 011341 Bucharest, Romania
}

\begin{abstract}
Analysis of cultural heritage artifacts represents a very important first step in any restoration/conservation attempt. Fourier-Transform Infrared Spectroscopy - Attenuated Total Reflectance (FTIR-ATR) technique can be successfully applied for the study of a wide range of historical artifacts (several papers describing the application of FTIR for the analysis of historical metals, paper, ceramic, fabrics, etc.). The present paper aims to present the application of FTIR-ATR for the characterization of historical fibers. The analyzed artifact represents a traditional pillowcase originating from Moldavia historical region, from the end of the XIX ${ }^{\text {th }}$ century - beginning of the $\mathrm{XX}^{\text {th }}$ century, belonging to a private collection. The technique offers some advantages because relatively small samples are directly analyzed after they are pressed against the surface of the diamond crystal without damaging the samples. Identification of fiber type enables sometimes to approximate the age of an artifact, the climate type or the trade routes and manufacturing process used. The artifact is formed of two major components: the support textile fiber and the colored fibers. The most encountered materials traditionally used for such objects are wool, flax and hemp. While wool is easily identified in the FTIR spectra due to its sharp and intense characteristic peaks, in the case of cellulosic fibers and especially for differentiation between flax and hemp fibers it was necessary to calculate the average values of the band intensity ratios $\mathrm{I}_{1595} / \mathrm{I}_{1105}$ and $\mathrm{I}_{1595} / \mathrm{I}_{2900}$.
\end{abstract}

Keywords: Historical textiles $\cdot$ FTIR-ATR spectroscopy $\cdot$ Colored textile Lignin

\section{Introduction}

The FTIR spectroscopy represents a valuable tool for the analysis of different types of historical artifacts due to its sensitivity, specificity and non-destructive character [1]. The technique can be successfully applied for characterization of metallic artifacts (such as iron [2] or bronze objects [3]), paper artifacts [4, 5], ancient ceramics [6] or historical textiles $[7,8]$. Chemical changes because of materials ageing can be observed 
and sometimes quantified using FTIR spectroscopy, which is important especially for art conservation efforts [9]. The identification of fibers originating from different natural materials: cotton, silk, wool, hemp, flax is of crucial importance to choose appropriate treatment and conservation strategies for textile artifacts, but also to ensure their proper exhibition [10, 11]. Moreover, specific knowledge of fiber type enables sometimes the approximate dating of an artifact, the type of climate a place had or the trade routes at a particular time together with information about the manufacturing process [11].

Analysis by FTIR in the field of historical textiles related to Romanian traditional fabrics can provide useful information regarding the type and origin of textile materials and dyes. It is well established that in Romania for the textile support mainly two types of cellulosic fibers were used (flax and hemp) and only one type of protein fiber (wool) [12]. Therefore, the range is relatively limited, making the investigation much easier from this point of view.

The first objective of conservation or reconstruction of textile artifacts is to determine the constitution of the fibers and this task is usually accomplished by performing FTIR spectra of different materials from different sources and regions and comparing with the spectra of artifacts [13].

\section{Experimental}

\section{$2.1 \quad$ Textile Material}

The analyzed textile artifact represents a traditional pillowcase originating from Moldavia historical region, manufactured at the end of the XIX ${ }^{\text {th }}$ century - beginning of the $\mathrm{XX}^{\text {th }}$ century (Fig. 1). From the large artifact, several smaller samples were obtained, representing both the support material and the colored fibers (Fig. 2). All the samples were analyzed as they were obtained from the original artifact (see Fig. 1).

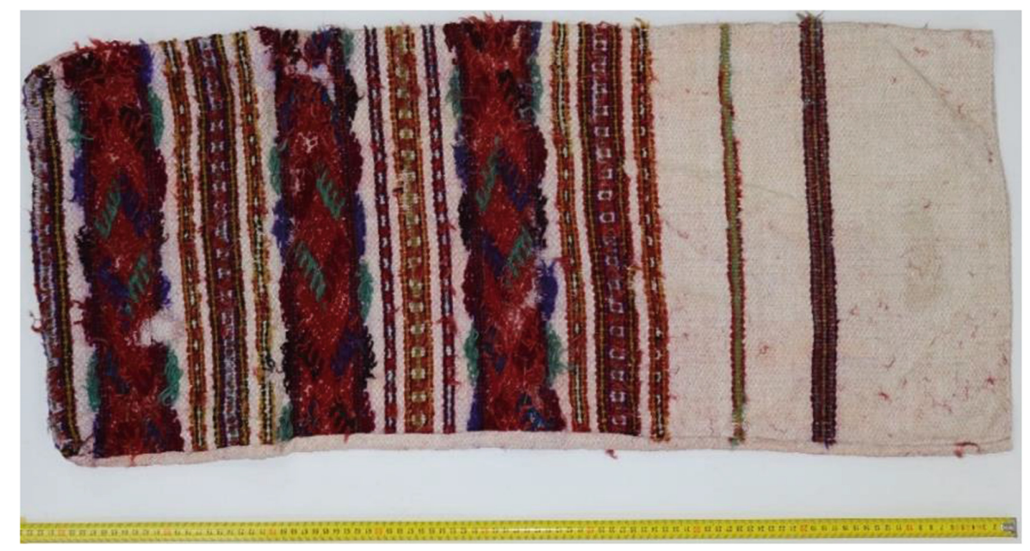

Fig. 1. The textile artifact studied (Color figure online) 


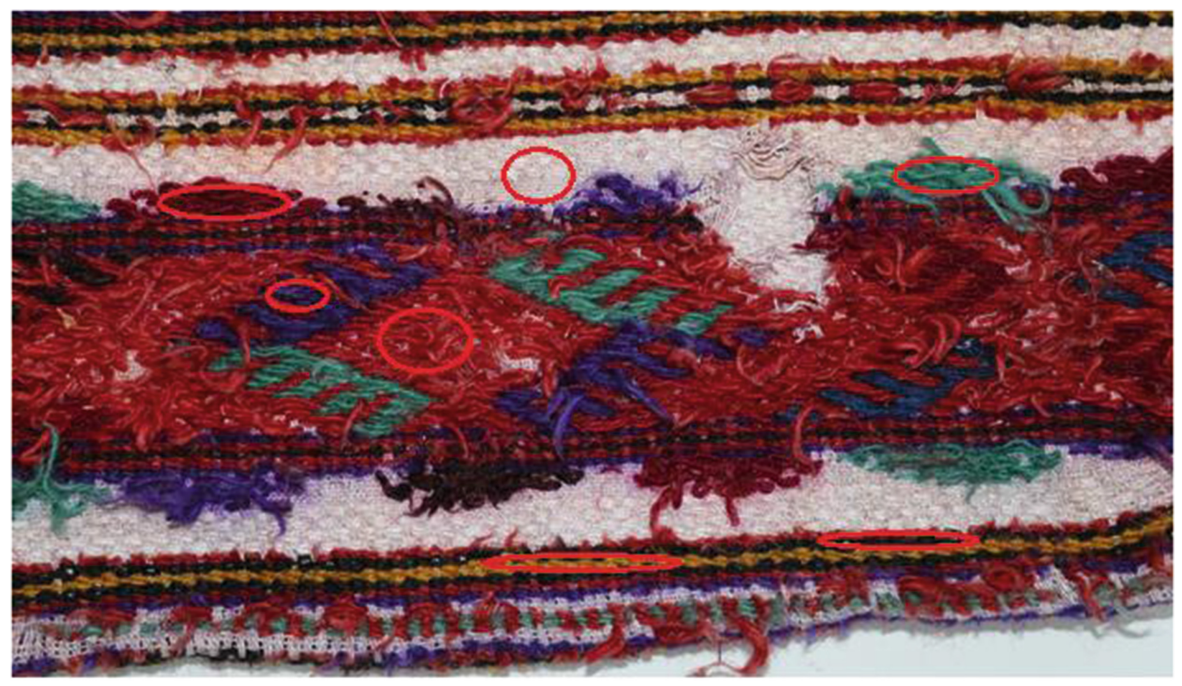

Fig. 2. Different collected samples from the artefact - the support material and the different colored samples (Color figure online)

\subsection{Analytical Method}

The FTIR spectra were recorded on a FTIR 6300 instrument from Jasco Inc., Japan, equipped with a Specac Golden Gate ATR which is fitted with a diamond crystal and an interaction angle of $45^{\circ}$. All the spectra recorded in the range $4000-400 \mathrm{~cm}^{-1}$ were averaged over 32 scans at a resolution of $4 \mathrm{~cm}^{-1}$. All the recorded data was processed with Spectra Manager II software from Jasco Inc., Japan.

\section{Results and Discussion}

In the field of natural dyes used as coloring materials, the major issue is related to the amount applied on the surface of the fiber, which is frequently situated bellow the detection limit in the infrared spectroscopy [14]. Thus, it is difficult to determine structural characteristics of the dyes directly from FTIR-ATR spectra of dyed textiles.

As it can be observed from the spectra of the samples obtained from a traditional pillowcase from Moldova historical region, the signals are specific to the textile support without interferences due to the presence of different dyes onto the surface of the fibers. The superimposed spectra of the colored fibers showed strong bands corresponding to amide I and amide II, situated at 1634 and $1511 \mathrm{~cm}^{-1}$, together with several other intense characteristic bands $\left(1390 \mathrm{~cm}^{-1}-\mathrm{CH}_{3}\right.$ symmetrical deformation and $1055 \mathrm{~cm}^{-1}$ - asymmetrical stretch C-O-C and C-N stretch), confirming that the textile support is wool in all the cases (Fig. 3). 


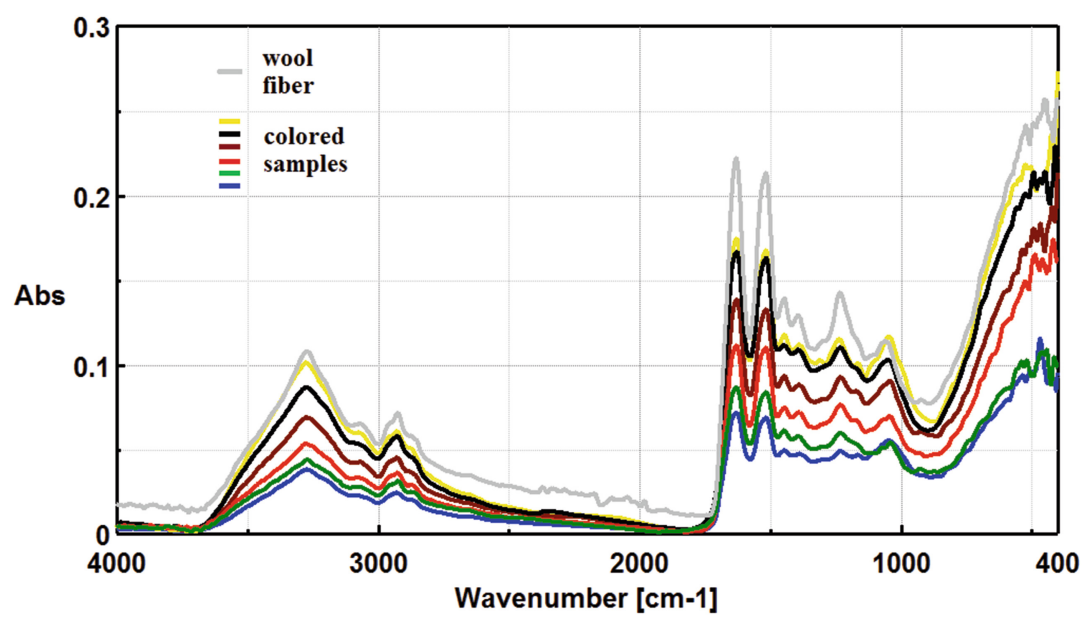

Fig. 3. FTIR-ATR spectra of colored samples from the textile artifact (Color figure online)

Spectra of cotton, flax and hemp recorded and compared with the white sample, which represents the artifact main material demonstrated similarities, as the main component of these fibers is cellulose and the other major component (hemicellulose) is a polysaccharide too. However, in deep analysis of the spectra showed certain differences, which can be used to differentiate them due to the lignin content (Table 1).

Table 1. The composition of some cellulosic fibers [15]

\begin{tabular}{l|l|l|l}
\hline Fibers & Cellulose (\%) & Hemicelluloses (\%) & Lignin (\%) \\
\hline Cotton & 82.7 & 5.7 & 0.0 \\
\hline Flax & 64.1 & 16.7 & 2.0 \\
\hline Hemp & 67.0 & 16.1 & 3.3 \\
\hline
\end{tabular}

As it was already established, the fibers can be differentiated from one another by calculating ratios between intensities of the infrared absorption bands at about 2900, 1595 and $1105 \mathrm{~cm}^{-1}$. These bands are associated with the $\mathrm{C}-\mathrm{H}$ stretching vibration (used as a measure of the overall organic content), the $\mathrm{C}=\mathrm{C}$ in plane aromatic vibrations (due to the lignin content) and the $\mathrm{C}-\mathrm{O}-\mathrm{C}$ glycosidic ether band (due to the cellulose content) [16].

The FTIR-ATR spectrum of the white sample, which is the main material of the artifact, reveals the presence of the characteristic peaks corresponding to cellulose and lignin and apparently may be hemp or flax (Fig. 4). The shape of the sample spectrum is closed to the flax spectrum, but for a reliable result the analysis of the intensity ratios must be calculated. 


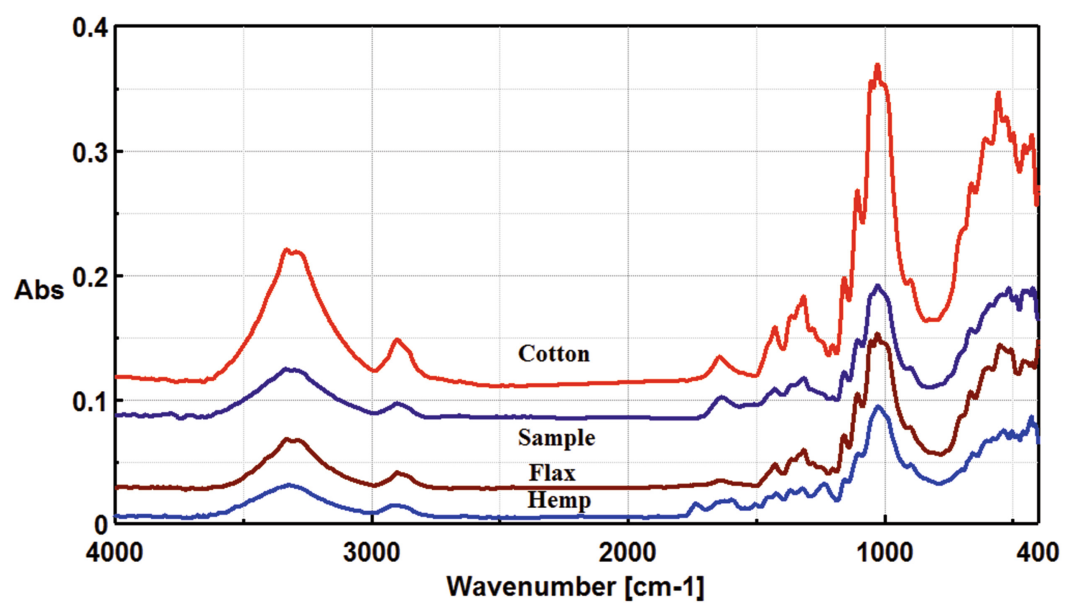

Fig. 4. FTIR-ATR spectra of possible textile fibers for the textile artifact main material

The average values of the band intensity ratios $\mathrm{R}_{1}\left(\mathrm{I}_{1595} / \mathrm{I}_{1105}\right)$ and $\mathrm{R}_{2}\left(\mathrm{I}_{1595} / \mathrm{I}_{2900}\right)$ were calculated for three types of pure cellulosic fibers (cotton, hemp and flax) and for the support sample (Table 2).

Table 2. The band intensity ratios $R_{1}\left(I_{1595} / I_{1105}\right)$ and $R_{2}\left(I_{1595} / I_{2900}\right)$

\begin{tabular}{l|l|l}
\hline Fibers & $\mathrm{R}_{1}\left(\mathrm{I}_{1595} / \mathrm{I}_{1105}\right)$ & $\mathrm{R}_{2}\left(\mathrm{I}_{1595} / \mathrm{I}_{2900}\right)$ \\
\hline Cotton & 0.33 & 0.11 \\
\hline Flax & 0.38 & 0.09 \\
\hline Hemp & 0.83 & 0.27 \\
\hline Sample & 0.41 & 0.10 \\
\hline
\end{tabular}

As it can be observed, the results obtained for the band intensity ratios do not follow exactly the composition of the fibers due to the overlapping of the bands in the regions where the measurements are made. An important task to be solved seems to be drying the samples before the measurements, because the water bending at about $1640 \mathrm{~cm}^{-1}$ artificially increased the band of lignin at $1595 \mathrm{~cm}^{-1}$. The deconvolution of the spectra does not solve the issue and if the measurement conditions remained unchanged, the results are consistent and the method can be used without restrictions to determine differences between cellulosic fibers. Valuable results that elucidate this kind of sensible difference probably can be obtained by performing polarized ATR-FTIR measurements [17]. As there is a great similarity among flax and hemp fibers, usually besides FT-IR spectroscopy it is necessary to perform investigations by complementary techniques, such as: the twist test, fiber diameter measurements, general microscopic observation, SEM analysis and polarized ATR spectroscopy completed whenever is possible with chemical tests (phloroglucionol reaction; Herzberg reagent, Schweitzer's reagent). 


\section{Conclusions}

Despite minor differences between different types of cellulosic fibers, FTIR-ATR technique proved to be a useful tool in order to distinguish them on the basis of some of their structural features.

Comparison between spectra of different cellulosic fibers, in terms of intensity ratios can lead to valuable results which allow differentiation even in the case of problematic species such as flax and hemp.

The fabric artifact studied by us is a traditional pillowcase originating from Moldavia historical region, from the end of the $\mathrm{XIX}^{\text {th }}$ century - beginning of the $\mathrm{XX}^{\text {th }}$ century, belonging to a private collection. The obtained results prove that it is formed of two types of fibers: the support textile fiber, identified as flax, and the colored fibbers, identified as wool fibers dyed with natural colorants. In order to analyze the natural colorants, present at the surface of the fibers, further investigations should be made and probably correlations with complementary techniques are necessary (such as extraction of the pigments and their analysis using High-performance liquid chromatography, SEM analysis etc.).

Acknowledgments. The authors gratefully acknowledge the financial support obtained through the project SoVaReX, Contract No. 10PS/2017, from the Sectorial Program - Romanian Ministry of Research and Innovation.

\section{References}

1. Peets, P., Leito, I., Pelt, J., Vahur, S.: Identification and classification of textile fibres using ATR-FT-IR spectroscopy with chemometric methods. Spectrochim. Acta Part A Molec. Biomolec. Spectrosc. 173, 175-181 (2017)

2. Ramesh Kumar, A.V., Balasubramaniam, R.: Corrosion product analysis of corrosion resistant ancient Indian iron. Corros. Sci. 39(6), 1169-1178 (1998)

3. Ion, R.M., et al.: Combined spectral analysis (EDXRF, ICP-AES, XRD, FTIR) for characterization of bronze roman mirror. Met. Int. 13(5), 61-65 (2008)

4. Fierascu, R.C., Avramescu, S.M., Vasilievici, G., Fierascu, I., Paunescu, A.: Thermal and spectroscopic investigation of Romanian historical documents from the nineteenth and twentieth century. J. Therm. Anal. Calorim. 123(2), 1309-1318 (2016)

5. Fierascu, I., et al.: Micro-analytical and microbiological investigation of selected book papers from the nineteenth century. J. Therm. Anal. Calorim. 129(3), 1377-1387 (2017)

6. Ion, R.M., et al.: Thermal and mineralogical investigations of historical ceramic: a case study. J. Therm. Anal. Calorim. 104(2), 487-493 (2011)

7. Akyuz, T., Akyuz, S., Balci, K., Gulec, A.: Investigations of historical textiles from the Imperial Pavilion (Hunkar Kasri) of the new mosque Eminonu-Istanbul (Turkey) by multiple analytical techniques. J. Cult. Herit. 25, 180-184 (2017)

8. Mai, H., Yang, Y., Jiang, H., Wang, B., Wang, C.: Investigating the materials and manufacture of Jinzi: the lining of Futou (Chinese traditional male headwear) from the Astana Cemeteries, Xinjiang, China. J. Cult. Herit. 27, 116-124 (2017)

9. Higgitt, C., Harris, S., Cartwright, C., Cruickshank, P.: Assessing the potential of historic archaeological collections: a pilot study of the British Museum's Swiss lake dwelling textiles. Br. Museum Techn. Res. Bull. 5, 81-94 (2011) 
10. Kavkler, K., Demsar, A.: Application of FTIR and Raman spectroscopy to qualitative analysis of structural changes in cellulosic fibres. Tekstilec 55(1), 19-31 (2012)

11. Chae, J.: Observation and analysis for identifying materials of textile objects. In: Conservation of Papers and Textiles, pp. 262-279. National Research Institute of Cultural Heritage, Daejeon (2011)

12. Olaru, A., Geba, M., Vlad, A.M., Ciovica, S.: Metallic accessories on ethnographic textiles deterioration problems. Eur. J. Sci. Theol. 9(3), 177-186 (2013)

13. Zemaityte, R., Jonaitiene, V., Milasius, R., Stanys, S., Ulozaite, R.: Analysis and identification of fibre constitution of archaeological textiles. Mater. Sci. (Medziagotyra) 12(3), 258-261 (2006)

14. De Luca, E., Bruni, S., Sali, D., Guglielmi, V., Belloni, P.: In situ nondestructive identification of natural dyes in ancient textiles by reflection fourier transform mid-infrared (FT-MIR) spectroscopy. Appl. Spectrosc. 69(2), 222-229 (2015)

15. Lewin, M., Pearce, E.M.: Handbook of Fiber Chemistry, 2nd edn. Marcel Dekker, Inc., New York (1998)

16. Garside, P., Wyeth, P.: Characterisation of plant fibres By infra-red spectroscopy. Polym. Prepr. 41(2), 1792-1793 (2000)

17. Garside, P., Wyeth, P.: identification of cellulosic fibres by FTIR Spectroscopy. Differentiation of flax and hemp by polarized ATR-FTIR. Stud. Conserv. 51, 205-211 (2006)

Open Access This chapter is licensed under the terms of the Creative Commons Attribution 4.0 International License (http://creativecommons.org/licenses/by/4.0/), which permits use, sharing, adaptation, distribution and reproduction in any medium or format, as long as you give appropriate credit to the original author(s) and the source, provide a link to the Creative Commons licence and indicate if changes were made.

The images or other third party material in this chapter are included in the chapter's Creative Commons licence, unless indicated otherwise in a credit line to the material. If material is not included in the chapter's Creative Commons licence and your intended use is not permitted by statutory regulation or exceeds the permitted use, you will need to obtain permission directly from the copyright holder.

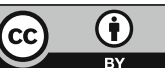

